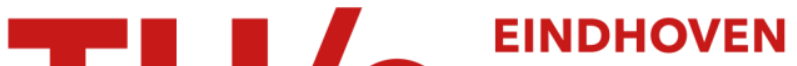 UNIVERSITY OF TECHNOLOGY
}

\section{A concise sensitivity analysis of the quasi-linear viscoelastic model proposed by Fung}

\section{Citation for published version (APA):}

Rousseau, E. P. M., \& Sauren, A. A. H. J. (1983). A concise sensitivity analysis of the quasi-linear viscoelastic model proposed by Fung. Journal of Biomechanical Engineering : Transactions of the ASME, 150(February), 9295.

Document status and date:

Published: 01/01/1983

\section{Document Version:}

Publisher's PDF, also known as Version of Record (includes final page, issue and volume numbers)

\section{Please check the document version of this publication:}

- A submitted manuscript is the version of the article upon submission and before peer-review. There can be important differences between the submitted version and the official published version of record. People interested in the research are advised to contact the author for the final version of the publication, or visit the $\mathrm{DOI}$ to the publisher's website.

- The final author version and the galley proof are versions of the publication after peer review.

- The final published version features the final layout of the paper including the volume, issue and page numbers.

Link to publication

\section{General rights}

Copyright and moral rights for the publications made accessible in the public portal are retained by the authors and/or other copyright owners and it is a condition of accessing publications that users recognise and abide by the legal requirements associated with these rights.

- Users may download and print one copy of any publication from the public portal for the purpose of private study or research.

- You may not further distribute the material or use it for any profit-making activity or commercial gain

- You may freely distribute the URL identifying the publication in the public portal.

If the publication is distributed under the terms of Article 25fa of the Dutch Copyright Act, indicated by the "Taverne" license above, please follow below link for the End User Agreement:

www.tue.nl/taverne

Take down policy

If you believe that this document breaches copyright please contact us at:

openaccess@tue.nl

providing details and we will investigate your claim. 


\section{Joumal of}

Biomechanical

Engineering

A Concise Sensitivity Analysis of the Quasi-Linear Viscoelastic Model Proposed by Fung

\section{A. A. H. J. Sauren and E. P. M. Rousseau ${ }^{1}$}

\section{Introduction}

The quasi-linear viscoelastic theory introduced by Fung [1] states that the constitutive equation relating stress $\sigma$ and strain $\epsilon$ for a soft biological tissue sample in simple elongation is given by the convolution integral ${ }^{2}$

$$
\sigma(t)=\int_{\tau=0}^{t} G(t-\tau) \sigma_{, \epsilon}^{(e)} \epsilon_{, \tau} d \tau
$$

with $\sigma(t)=0$ and $\epsilon(t)=0$ for $t<0$,

$$
G(0)=1 \text {. }
$$

The dependence of stress on both strain and time is separately described by the nonlinear elastic response $\sigma^{(e)}(\epsilon)$ and the reduced relaxation function $G(t)$, respectively.

In order to account for the remarkable strain rate insensitivity of both the stress-strain relation and the hysteresis loop of many soft biological tissues, Fung [1] proposed a specific relaxation spectrum of the form

$$
S(\tau)= \begin{cases}C / \tau & \text { for } 0<\tau_{1} \leq \tau \leq \tau_{2} \\ 0 & \text { elsewhere }\end{cases}
$$

where $C$ represents a dimensionless positive constant and $\tau_{1}$ and $\tau_{2}$ are time constants. This yields for the reduced relaxation function (RRF)

$$
G(t)=\left[1+C\left\{E_{1}\left(t / \tau_{2}\right)-E_{1}\left(t / \tau_{1}\right)\right\}\right] /\left[1+C \ln \left(\tau_{2} / \tau_{1}\right)\right]
$$

with $E_{1}(x)=\int_{y=x}^{\infty}(\exp (-y) / y) d y$, the exponential integral function.

An important quantity for the description of the frequencydependent behavior is the loss angle

\footnotetext{
${ }^{1}$ Eindhoven University of Technology, Department of Mechanical Engineering, Eindhoven, The Netherlands

${ }^{2}$ The notation $y_{x}=\frac{\partial y}{\partial x}$ is used.

Contributed by the Bioengineering Division for publication in the JoURNAI Contributed by the Bioengineering Diongineering OF BIOMECEANICAL ENGIN June 28, 1982; revised manuscript received August 2, 1982.
}

$$
\begin{aligned}
\phi= & \arctan \left(E_{l} / E_{s}\right) \\
= & \arctan \left(C\left\{\arctan \left(\omega \tau_{2}\right)-\arctan \left(\omega \tau_{1}\right)\right\} /\{1+(C / 2) \mathrm{ln}\right. \\
& {\left.\left.\left[\left\{1+\left(\omega \tau_{1}\right)^{2}\right\} /\left\{1+\left(\omega \tau_{1}\right)^{2}\right\}\right]\right\}\right) . }
\end{aligned}
$$

$E_{l}$ and $E_{s}$ represent the loss and storage modulus, respectively; i.e., the imaginary and real parts of the complex modulus $E=E_{s}+i E_{l}$ which relates stress and strain during sinusoidal excitation in the steady state. The loss angle $\phi$ governs the description of the viscous losses: $\phi=0$ and $\phi=\pi / 2$ correspond with purely elastic and purely viscous behavior, respectively.

For the quantitative description of the viscoelastic properties of various types of soft biological tissues this quasilinear viscoelastic model has yielded satisfactory results [2-9].

Using this model for the analysis of the relaxation behavior of aortic valve tissues in our laboratories the need was felt to obtain more insight into the importance of the parameters $C$, $\tau_{1}$ and $\tau_{2}$ for the description of certain viscoelastic phenomena.

\section{Methods and Results}

Before exploring the influence of the parameters $C, \tau_{1}$ and $\tau_{2}$ on the reduced relaxation function $G(t)$ and the loss angle $\phi(\omega)$, some remarks will be made on the general features of the model.

Although it is intended to describe viscoelastic phenomena, the question arises whether it is also capable of describing the extremes of the range covered by viscoelastic behavior, namely purely elastic and purely viscous behavior. For a purely elastic material will apply $G(t)=1$ and $\phi(\omega)=0$. From equations (3) and (4) is it seen that this requirement is met by setting $C=0$. In the case of purely viscous behavior the complex modulus will be purely imaginary. This implies that the storage modulus equals zero

$$
E_{S}=C_{R}\left[1+(C / 2) \ln \left\{\left(1+\left(\omega \tau_{2}\right)^{2}\right) /\left(1+\left(\omega \tau_{1}\right)^{2}\right)\right\}\right]=0 .
$$

$C_{R}$ represents the stiffness exhibited by the material under quasi-static strain or load and will always be positive. Thus with $C_{R} \neq 0$ and $C>0$ it follows that equation (5) can be satisfied only if $\tau_{1}>\tau_{2}$. This is in contradiction with the requirement $\tau_{2}>\tau_{1}$, stated in equation (2). Consequently it is concluded that the quasi-linear viscoelastic model based upon the relaxation spectrum (2) is not capable of describing purely viscous behavior.

In the following the partial derivatives with respect to $C, \tau_{1}$ and $\tau_{2}$ of the initial slope $\left(G, t_{t=0}\right.$ and the final (constant) value $G(\infty)=\lim G(t)$ of $G(t)$ will be considered (Fig. 1).

The initial reduced relaxation rate $r_{0}$, i.e., the rate by which the RRF initially decreases, is given by

$$
r_{0}=-\left(G_{, t}\right)_{t=0}=C\left(1 / \tau_{1}-1 / \tau_{2}\right) /\left[1+C \ln \left(\tau_{2} / \tau_{1}\right)\right] .
$$

From equation (3) the final relaxation fraction, i.e., the 


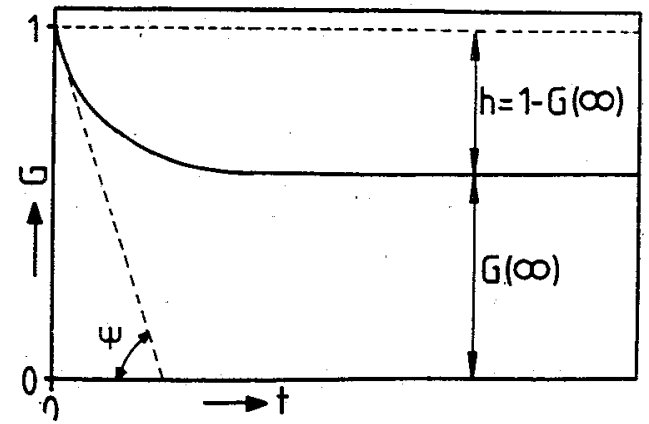

Fig. 1 Outline of the reduced relaxation function $G ; r_{0}=$ $-\left(G_{, t}\right)_{t=0}=\tan (\psi)$ : initial reduced relaxation rate; $h$ : final relaxation Iraction

fraction of the instantaneous stress response of $t=0)$ that has vanished after stress relaxation has ceased, is found to be

$$
h=1-G(\infty)=1-\left[1+C \ln \left(\tau_{2} / \tau_{1}\right)\right]^{-1} .
$$

Using the abbreviations $\alpha=\left(1 / \tau_{1}-1 / \tau_{2}\right)$ and $\beta=\ln \left(\tau_{2} / \tau_{1}\right)$, the partial derivatives can be written as

$$
\begin{aligned}
r_{0, C} & =\alpha /(1+\beta C)^{2}, \\
r_{0, \tau_{1}} & =-C[1+C\{\beta-1+\exp (-\beta)\}] /\left[\tau_{1}(1+\beta C)\right]^{2}, \\
r_{0, \tau_{2}} & =C[1+C\{\beta+1-\exp (\beta)\}] /\left[\tau_{2}(1+\beta C)\right]^{2}, \\
h_{, C} & =\beta /(1+\beta C)^{2}, \\
h_{, \tau_{1}} & =-C /\left[\tau_{1}(1+\beta C)^{2}\right],
\end{aligned}
$$

and

$$
h_{, \tau_{2}}=C /\left[\tau_{2}(1+\beta C)^{2}\right] .
$$

Taking into consideration that $\alpha>0$ and $\beta>1$ because $0<\tau_{1}<\tau_{2}$, and that $C>0$, it can be seen immediately from the foregoing equations that $r_{0, C}>0, r_{0, \tau_{1}}<0, h_{, C}>0, h_{, r_{1}}<0$ and $h_{, \tau_{2}}>0$. Some more investigation is needed to decide on the sign of $r_{0, \tau_{2}}$. The sign of $r_{0, \tau_{2}}$ is equal to that of the term between square brackets in the numerator of equation (10). From the values of this term for various soft tissues, determined from data in literature and listed in Table 1 , it is readily concluded that $r_{0, \tau_{2}}<0$. From equations (12) and (13) it follows with $\tau_{1}<\tau_{2}$ that $\left|h_{, \tau_{1}}\right|>\left|h_{, \tau_{2}}\right|$, which means that the long-term relaxation behavior will be more affected by $\tau_{1}$ than by $\tau_{2}$.

To illustrate the foregoing the following set of parameter values was chosen: $C=0.05, \tau_{1}=0.005 \mathrm{~s}, \tau_{2}=50 \mathrm{~s}$. These values were multiplied in turn with a constant $c(c=0.1$ and 10), while the other two were kept at their original value (corresponding with $c=1$ ). For each set $r_{0}$ and $h$ were determined to get an indication on the sensitivity of $r_{0}$ and $h$ as to changes in $C, \tau_{1}$ and $\tau_{2}$. The results are listed in Table 2 and illustrated in Fig. 2. It is readily observed that the initial reduced relaxation rate $r_{0}$ is mainly governed by $\tau_{1}$ and $C$. An increase of $\tau_{1}$ and $C$ corresponds with a decrease and an increase of the relaxation rate, respectively. The effect of changes in $\tau_{2}$ on $r_{0}$ is very small. The long-term relaxation behavior is most strongly affected by the value of $C$ : increase of $C$ results in an increase of stress relaxation. In comparison the influence of $\tau_{1}$ and $\tau_{2}$ is negligible.

The investigation of the loss angle $\phi(\omega)$ is mathematically

\begin{tabular}{|c|c|c|}
\hline $1+C(\beta+1-\exp (\beta))$ & Tissue & Reference \\
\hline $\begin{array}{l}-2.4408 \times 10^{7} \\
-48.80 \\
-31.30 \\
-28.16 \\
-19.13 \\
-2804 \\
=6557 \\
-12759 \\
-3058 \\
-18590 \\
-441 \\
-6558 \\
-17848 \\
-4776\end{array}$ & $\left.\begin{array}{l}\text { Rabbit mesentery } \\
\text { Arch circumf. }{ }^{(a)} \\
\text { Arch axial }{ }^{(b)} \text { circumf. } \\
\text { Prox.thor. } \\
\text { Prox.thor. axial } \\
\text { Articular cartilage } \\
\text { Rabbit papillary muscie] } \\
\text { Cat papillary muscle } \\
\text { Leaflet circumf. } \\
\text { Leaflet radial } \\
\text { Sinus circumf. } \\
\text { Sinus axial } \\
\text { Aorta circumf. } \\
\text { Aorta axial }\end{array}\right]$ & $\begin{array}{l}\text { Chen and Fung [3] } \\
\text { Tanaka and Fung [5] } \\
\text { Woo, et al. [7] } \\
\text { Pinto and Patitucci [6] } \\
\text { Sauren [9] }\end{array}$ \\
\hline
\end{tabular}
more complicated. After rewriting equation (4) as

$$
\phi=\arctan (\gamma)
$$

with

Table 1 Values of the term between square brackets in the numerator of equation (10), determined for various tissues from data in literature

${ }^{(a)}$ Circumferential

(b) Proximal thoracic

Table 2

(a)Effects upon the initial reduced relaxation rate $r_{0}$ of variations of $C, \tau_{1}$ and $\tau_{2}$ about the set of center values $C=0.05, \tau_{1}=0.05(s)$ and $\tau_{2}=50(s)$. Between parentheses the quotient of the actual value and the center value of $r_{0}$ (corresponding with $c=1$ ) is given.

\begin{tabular}{lccc}
\hline$c$ & 0.1 & 1 & 10 \\
\hline$C$ & $0.96(0.14)$ & $6.85(1)$ & $17.84(2.60)$ \\
$\tau_{1}$ & $63.46(9.26)$ & & $0.74(0.11)$ \\
$\tau_{2}$ & $7.42(1.08)$ & & $6.35(0.93)$ \\
\hline$(b)$ Idem for the final relaxation fraction $h$ & 1 & \\
\hline$c$ & 0.1 & $0.32(1)$ & 10 \\
\hline$C$ & $0.04(0.12)$ & & $0.82(2.56)$ \\
$\tau_{1}$ & $0.36(1.12)$ & & $0.26(0.81)$ \\
$\tau_{2}$ & $0.19(0.59)$ & & $0.31(0.97)$ \\
\hline
\end{tabular}




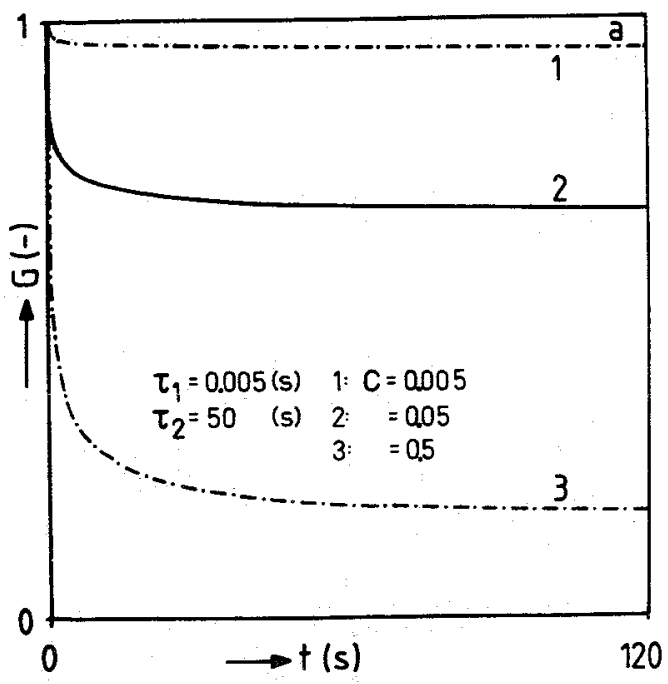

(a)

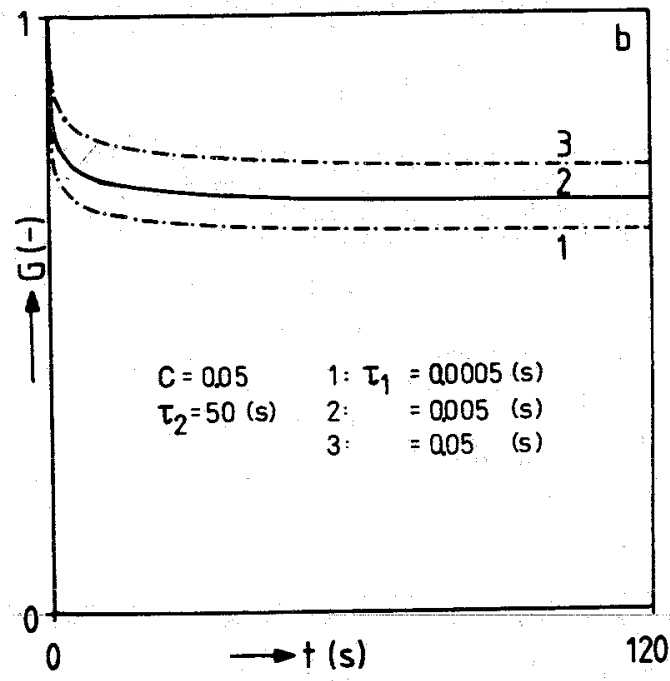

(b)

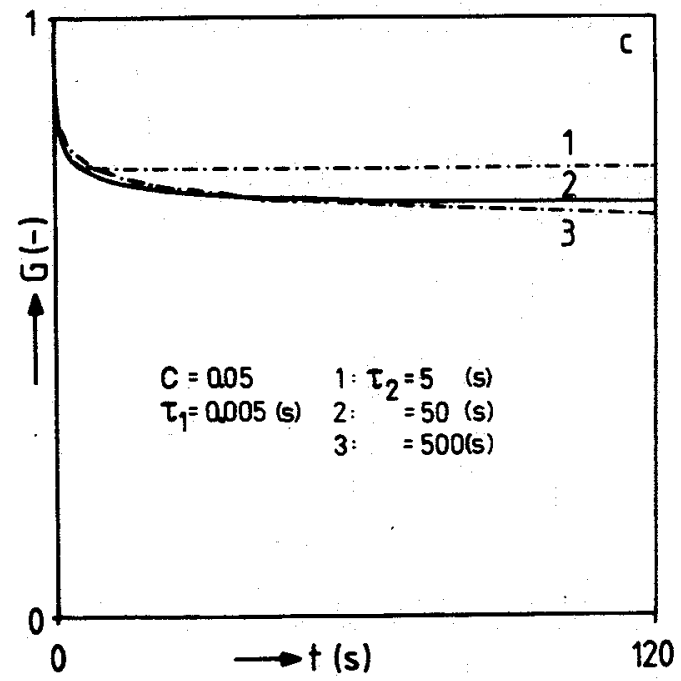

(c)

Fig. 2 Graphical illustration of the influence of parameter variations about a set of center values (see Table 2) upon the reduced relaxation function. The figures (a) through (c) show the effects of changes in $C, \tau_{1}$ and $\tau_{2}$, respectively. The solid curve in each figure represents the characteristic corresponding with the set of center values.

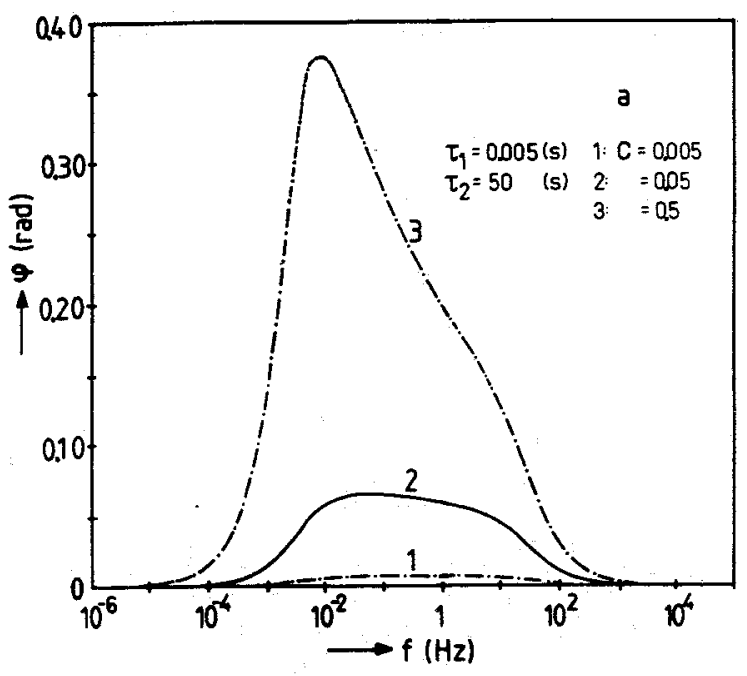

(a)

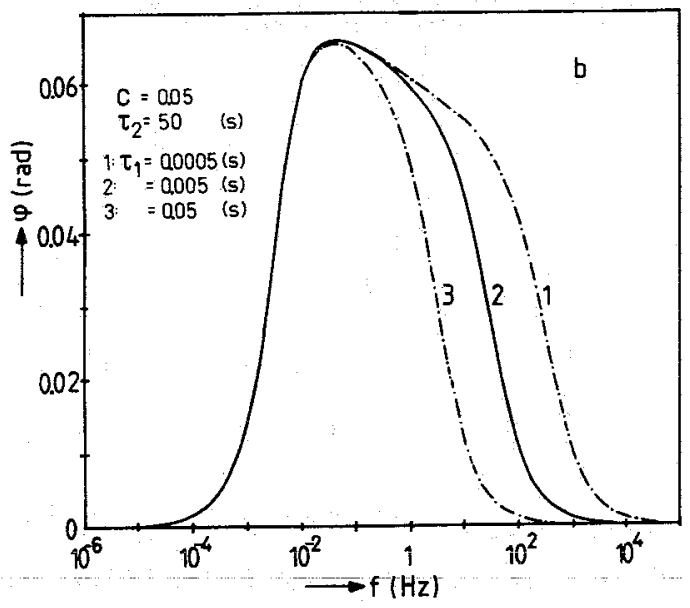

(b)

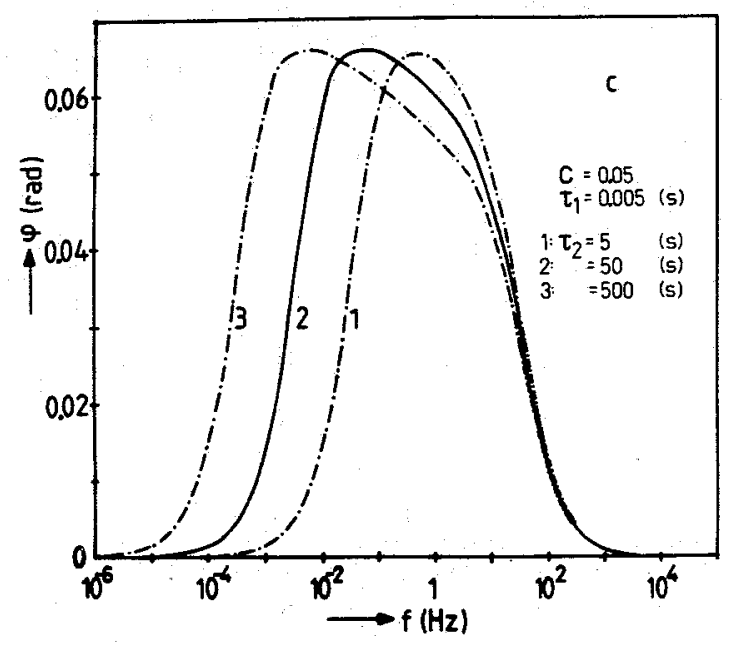

(c)

Fig. 3 Graphical illustration of the influence of parameter variations upon the loss angle. For further explanation see text of Fig. 2. Note the different scaling factors on the vertical axes. 


$$
\begin{aligned}
\gamma= & C\left\{\arctan \left(\omega \tau_{2}\right)-\arctan \left(\omega \tau_{1}\right)\right\} \\
& /\left\{1+(C / 2) \ln \left[\left\{1+\left(\omega \tau_{2}\right)^{2}\right\} /\left\{1+\left(\omega \tau_{1}\right)^{2}\right\}\right]\right\}
\end{aligned}
$$

the partial derivative $\phi_{, x}$ appears to be of the form

$$
\phi_{, x}=\gamma_{, x} /\left(1+\gamma^{2}\right) \text { with } 0<1 /\left(1+\gamma^{2}\right) \leq 1 \text {. }
$$

The sign of $\phi_{, x}$ will be equal to that of $\gamma, x$. Therefore an examination of the partial derivatives of $\gamma$ will be sufficient. Using the abbreviation

$$
g=1+(C / 2) \ln \left[\left\{1+\left(\omega \tau_{2}\right)^{2}\right\} /\left\{1+\left(\omega \tau_{1}\right)^{2}\right\}\right]
$$

we get

$$
\begin{aligned}
& \gamma, C=\left\{\arctan \left(\omega \tau_{2}\right)-\arctan \left(\omega \tau_{1}\right)\right\} / g^{2}, \\
& \gamma_{, \tau_{1}}=C \omega\left(\omega \tau_{1} \gamma-1\right) /\left[g\left\{1+\left(\omega \tau_{1}\right)^{2}\right\}\right]
\end{aligned}
$$

and

$$
\gamma_{, \tau_{2}}=C \omega\left(1-\omega \tau_{2} \gamma\right) /\left[g\left[1+\left(\omega \tau_{2}\right)^{2}\right\}\right] .
$$

With $\tau_{1}<\tau_{2}$ it follows immediately from equation (17) that always will apply $\gamma, C \geq 0$. However, from equations (18) and (19) it is seen that the sign of the derivatives $\gamma_{, \tau_{1}}$ and $\gamma_{, \tau_{2}}$ will depend in general on the actual values of $C, \tau_{1}, \tau_{2}$ and $\omega$. A detailed mathematical analysis of the equations (18) and (19) would go far beyond the scope of this paper. Instead we will restrict ourselves to a graphical illustration of the effects on $\phi$ of variations in $\tau_{1}$ and $\tau_{2}$ (see Fig. 3). The loss angle is highly sensitive to changes in $C$. A decrease of $C$ results not only in a decrease of $\phi$ at a particular frequency (as indicated by equation (17)), but also causes a flattening of the $\phi$ curve: the material behavior becomes more and more elastic with decreasing. $C$. Variations of $C$ and $\tau_{1}$ have a negligible influence upon the value of the frequency at which $\phi$ is maximum, whereas an increase of $\tau_{2}$ results in a considerable shift of this frequency towards lower values. The maximum value of $\phi$, however, is insensitive to variations of the time constants $\tau_{1}$ and $\tau_{2}$ but is strongly affected by the parameter $C$. The curves in Figs. $3(b)$ and $(c)$ illustrate clearly the pronounced influence of $\tau_{1}$ and $\tau_{2}$ upon, respectively, the parts on the $\phi$ curves beyond and below their maximum: "slow" viscous phenomena are mainly affected by $\tau_{2}$, whereas $\tau_{1}$ governs the "fast" phenomena.

The foregoing may be summarized as follows: The parameter $C$ is the most important as it determines the degree to which viscous effects are present. The time constants $\tau_{1}$ and $\tau_{2}$ govern, respectively, the "fast" and "slow" viscous phenomena.

\section{Acknowledgments}

The authors are greatly indebted to Mrs. M. van Boxtel and Mr. L. Wouters for their help in preparing the manuscript.

\section{References}

1 Fung, Y. C. B., "Stress-Strain History Relations of Soft Tissues in Simple Elongation," Biomechanics: Its Foundations and Objectives, eds., Y. C. Fung, N. Perrone, and M. Anliker, Chap. 7, Prentice Hall, N.J., 1972, pp. $181-208$.

2 Haut, R. C., and Little, R. W., "A Constitutive Equation for Collagen Fibers;"Journal of Biomechanics, Vol. 5, 1972, pp. 423-430.

3 Chen, Y. L., and Fung, Y. C., "Stress-Strain History Relations of Rabbit Mesentery in Simple Elongation," Biomechanical Symposium, AMD-2, ASME, 1973, pp. 9-10.

4 Jenkins, R. B., and Little, R. W., "A Constitutive Equation for ParallelFiber Elastic Tissue," Journal of Biomechanics, Vol. 7, 1974, pp. 397-402.

5 Tanaka, T. T., and Fung, Y. C., "Elastic and Inelastic Properties of the 5 Tanaka, T. T., and Fung, Y. C., "Elastic and Along the Aortic Tree," Journal of Biomechanics, Vol. 7, 1974, pp. 357-370.

6 Pinto, J. C, and Patitucci, P. "Visco-Elasticity of Passive Cardiac 6 Pinto, J. C., and Patitucci, P. Journal of BIomechanical ENGineERING, Vol. 102, 1980,

pp. 57-61. 7 Woo, S. L.-Y., Simon, B. R., Kuel, S. C., and Akeson, W. Cartilage,", ASME Linear Viscoelastic Properties of Normal Articular Car. 198 , pp.

Journal of BiomechaniCAL ENGINEERING, Vol. 102, 1980, pp. "The Time and

8 Woo, S. L.-Y., Gomez, M. A., and Akeson, W. H., The Time and History-Dependent Viscoelastic Properties of the Canine Medial Collateral Ligament," ASME Jovrnal of BIOMECHANICAL ENGINEERING, Vol. 103, 1981 pp. 293-298.

9 Sauren, A. A. H. J., "The Mechanical Behaviour of the Aortic Valve," Ph.D. dissertation, Eindhoven University of Technology, Eindhoven, The Netherlands, 1981. 